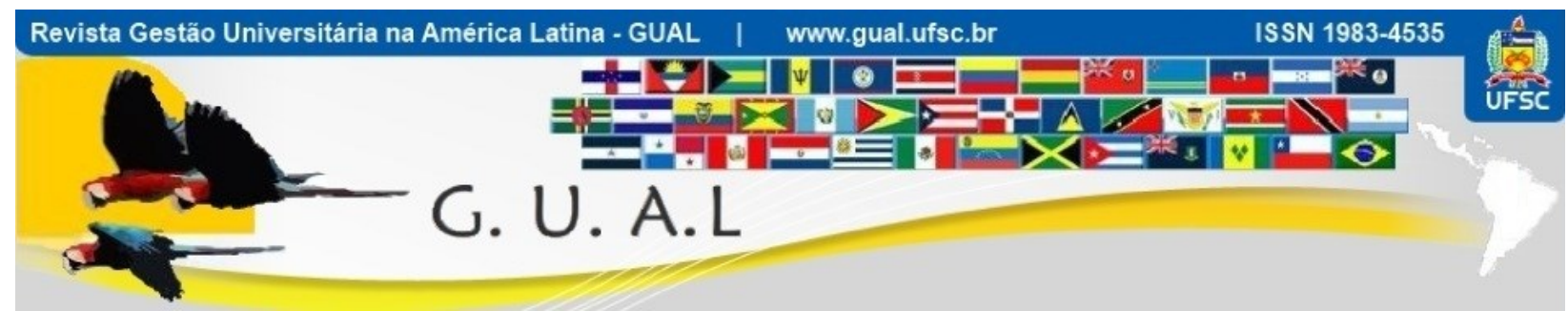

DOI: http://dx.doi.org/10.5007/1983-4535.2014v7n2p47

\title{
ESTÁGIO NÃO OBRIGATÓRIO: CONTRIBUIÇÕES PARA A FORMAÇÃO ACADÊMICA E PROFISSIONAL DO ESTUDANTE DA UNIVATES
}

\author{
NON-MANDATORY INTERNSHIP: ITS CONTRIBUTIONS TO ACADEMIC \\ EDUCATION AND PROFESSIONAL TRAINING FOR THE STUDENTS AT \\ UNIVATES
}

\author{
Jaqueline Lavall, Especialista \\ Centro Universitário UNIVATES \\ jaquelinelavall@gmail.com \\ Júlia Elisabete Barden, Doutora \\ Centro Universitário UNIVATES \\ jbarden@univates.br
}

Recebido em 08/maio/2013

Aprovado em 24/março/2014

Sistema de Avaliação: Double Blind Review

Esta obra está sob uma Licença Creative Commons Atribuição-Uso. 


\title{
ESTÁGIO NÃO OBRIGATÓRIO: CONTRIBUIÇÕES PARA A FORMAÇÃO ACADÊMICA E PROFISSIONAL DO ESTUDANTE DA UNIVATES \\ DOI: http://dx.doi.org/10.5007/1983-4535.2014v7n2p47
}

\begin{abstract}
RESUMO
O presente trabalho tem como objetivo verificar as contribuições do estágio não obrigatório para a formação acadêmica e profissional dos estudantes da Univates. Para atingir esse objetivo, buscou-se compreender o perfil dos estagiários, cursos e empresas concedentes, a relação estabelecida entre a teoria com a prática e com o mercado de trabalho, além de verificar a necessidade de adotar novas práticas pela Univates em relação aos estágios não obrigatórios de seus estudantes. A revisão da literatura trata de temas como a evolução do estágio no Brasil, aspectos da Lei $\mathrm{n}^{\mathrm{o}} 11.788 / 08$, que regulamenta o estágio não obrigatório, e conceitos de estágio. No que se refere à metodologia, trata-se de um estudo exploratório, realizado por meio de pesquisa bibliográfica e levantamento. Os resultados apontam que o estágio não obrigatório contribui de forma positiva para a formação acadêmica e profissional dos estudantes. Em contrapartida, foi revelado certo descontentamento com a supervisão realizada pela Univates, o que pode ser visto como uma oportunidade de melhoria para a Instituição.
\end{abstract}

Palavras-chave: Estágio não obrigatório. Formação. Mercado de trabalho.

\begin{abstract}
This paper aims at verifying the contributions of the non-mandatory internship to academic education and professional training for the students at Univates. In order to do this, we attempted to understand the profile of interns, courses and companies granting internships, the relationship established among theory, practice and labor market, as well as to analyze the need for Univates to adopt new practices regarding non-mandatory internships for its students. Literature review approached themes such as the evolution of internship in Brazil, aspects of Law 11.788/08, which regulates the non-mandatory internship, and concepts of internship. Regarding methodology, this is an exploratory study, carried out through bibliographic research and survey. Outcomes indicate that the non-mandatory internship contributes positively to the academic education and professional training of the students; however, a certain dissatisfaction with Univates supervision has been revealed, which may be considered an aspect to be improved by the institution.
\end{abstract}

Key-Words: Non-mandatory internship. Education. Labor Market. 


\section{INTRODUÇÃO}

$\mathrm{O}$ mercado de trabalho, por ser voltado à produtividade e resultados, exige mentes dotadas de capacidade de produzir e utilizar o conhecimento. De acordo com Souza, Cabral e Viana (2010), a competitividade não é mais decidida pela tecnologia ou capacidade de produção, mas pelas pessoas. Para os autores, a formação garante vantagem competitiva aos jovens, preparando-os de forma condizente com o exigido pelo mercado de trabalho.

Além disso, as diversas mudanças no mundo empresarial exigem profissionais cada vez mais capacitados, que cheguem às empresas com competências e habilidades já desenvolvidas, para que não seja necessário aprimorá-las durante a carreira. O futuro profissional precisa conhecer o mercado de trabalho e as pessoas e organizações que o cercam, pois o conhecimento dos colaboradores, não somente o teórico, está se transformando no recurso que agrega valor às empresas (Souza, Cabral e Viana, 2010).

Diante desse contexto, existe a necessidade de os estudantes passarem por experiências práticas no mercado de trabalho, para que possam complementar a sua formação acadêmica, sendo o estágio não obrigatório uma das formas mais utilizadas para conseguir experiência profissional. Isso porque ele posiciona o aluno frente às dificuldades do mundo empresarial e de sua futura profissão, desenvolvendo as habilidades e competências necessárias para entrar no mercado de trabalho. Como experiência profissional, o estágio não obrigatório volta-se para o desenvolvimento de ações vivenciadas, reflexivas e críticas. Tratase de aprendizagem, mas com características específicas, como elemento integrador e interdisciplinar, oportunizando a inserção de alunos e professores na realidade profissional existente.

Percebe-se que o estágio não obrigatório é importante para a formação dos jovens, não sendo esta realidade diferente para os estudantes do Centro Universitário UNIVATES. No segundo semestre letivo de 2012, a Univates contava com uma média mensal de 792 alunos realizando estágio nessa modalidade, matriculados em 52 cursos e distribuídos entre 266 empresas concedentes. Assim, o presente estudo tem como objetivo verificar as contribuições do estágio não obrigatório para a formação acadêmica e profissional do aluno da Univates, baseado na percepção do estudante, da empresa concedente e dos professores supervisores dos cursos mantidos por essa Instituição de Ensino Superior. O objetivo principal se desdobra nos seguintes objetivos específicos: 


\section{ESTÁGIO NÃO OBRIGATÓRIO: CONTRIBUIÇÕES PARA A FORMAÇÃO ACADÊMICA E \\ PROFISSIONAL DO ESTUDANTE DA UNIVATES \\ DOI: http://dx.doi.org/10.5007/1983-4535.2014v7n2p47}

- verificar se o estágio não obrigatório permite ao estudante oportunidade de reflexão, para ajudar a definir a sua futura carreira;

- verificar se o estágio não obrigatório possibilita a aplicação prática dos conhecimentos adquiridos no curso e a obtenção de experiências úteis ao futuro profissional;

- determinar os benefícios do estágio não obrigatório, o que pode levar o estudante a procurar a atividade de estágio e as empresas concedentes a contratarem estagiários; supervisores.

- detectar as dificuldades encontradas pelo estagiário, empresas e professores

O interesse em abordar essa questão decorre das novas exigências que se colocam para o ensino superior: oferecer formação condizente com as constantes transformações do mercado de trabalho. Segundo Albuquerque e Silva (2006, p.1), "o papel das universidades é preparar o aluno para o exercício profissional, criando condições para integrá-lo, sem maiores dificuldades, no mercado de trabalho". Assim, torna-se cada vez mais necessário proporcionar aos estudantes aprendizagem em situações reais de trabalho desde o início dos estudos. Mas, para isso, é necessária sintonia entre instituição de ensino e estudante, verificando se as condições utilizadas para esse aprendizado são favoráveis.

\section{FUNDAMENTAÇÃO TEÓRICA}

De acordo com o Instituto Euvaldo Lodi - IEL (2010), o surgimento do estágio no Brasil está ligado à evolução da educação no país, pois se trata de uma atividade curricular.

Vasconcelos (2010) relata que as primeiras instituições de ensino superior surgiram no Brasil após a chegada da Família Real Portuguesa, em 1808, tendo as primeiras universidades sido a Escola de Medicina do Rio de Janeiro, a Escola de Medicina da Bahia e a Escola de Engenharia e Arte Militar do Rio de Janeiro. A partir de 1889, as escolas de nível superior começaram a se difundir pelo Brasil de acordo com as necessidades econômicas da época.

Já a preocupação com a efetiva qualidade do ensino surgiu em 1996, com a Lei de Diretrizes e Bases para a Educação Nacional (Lei nº 9.394/96). Desde então, o ensino superior tem sido avaliado constantemente, o que trouxe maior expansão e qualificação da educação. De acordo com o Censo da Educação Superior de 2010, o Brasil conta com 6.379.299 estudantes no ensino superior, matriculados em 2.378 Instituições. Esses números demonstram o crescimento do ensino superior no país, principalmente no setor privado, que conta com $74,2 \%$ das matrículas. Outro comprovante da expansão do ensino é o número de estudantes concluintes de curso nos últimos anos: em 2001 eram 396.119 alunos, enquanto que em 2010 o total de formandos chegou a 973.839. Esse crescimento faz com que a relação 


\section{ESTÁGIO NÃO OBRIGATÓRIO: CONTRIBUIÇÕES PARA A FORMAÇÃO ACADÊMICA E \\ PROFISSIONAL DO ESTUDANTE DA UNIVATES \\ DOI: http://dx.doi.org/10.5007/1983-4535.2014v7n2p47}

educação-trabalho passe a ter cada vez mais importância para alunos e empresas, pois contribui para que aumente a demanda por estágios não obrigatórios.

Essa relação é relativamente nova na legislação brasileira, considerando que a sua primeira menção ocorreu na década de 30. Segundo Lima Filho (2009, texto digital),

[...] pode-se afirmar que a primeira norma que fez menção à figura do estagiário foi o art. $4^{\circ}$ do Decreto ${ }^{\circ} 20.294$, de 12 de agosto de 1931, ao permitir que a Sociedade Nacional de Agricultura admitisse, mediante acordo com o Ministério da Agricultura, nas escolas, alunos estagiários recebendo para isso, uma dotação anual por estudante matriculado.

A partir de então, diversas normas específicas que relacionavam educação e trabalho foram publicadas. No entanto, Probst apud Fujino e Vasconcelos (2011) destaca que o estágio não obrigatório era tratado como uma atividade desenvolvida no mundo do trabalho, não havendo preocupação com o aspecto pedagógico do aprendizado. Essa situação foi alterada em 1977, quando foi promulgada a Lei $\mathrm{n}^{\circ}$ 6.494, autorizando o estágio de estudantes em estabelecimento de ensino superior e de ensino profissionalizante de $2^{\circ}$ grau (atual ensino médio) e supletivo, além de definir quem poderia estagiar e os envolvidos nessa atividade.

Por mais de 30 anos essa lei não passou por alterações e foi regulamentada pelo Decreto $\mathrm{n}^{\mathrm{o}}$ 87.497/1982. No entanto, a economia e o mercado de trabalho no Brasil evoluíram, fazendo com que o estágio não obrigatório tivesse uma regulamentação ultrapassada e fosse utilizado como mão de obra barata por diversas empresas.

Com isso, em 25 de setembro de 2008, foi sancionada a Lei $\mathrm{n}^{\circ} 11.788$, conhecida como Nova Lei de Estágios, que trouxe avanços e proteção ao estudante. De acordo com o IEL (2010), uma das importantes razões para essa mudança foi a necessidade de transformar o estágio em ferramenta capaz de, verdadeiramente, contribuir para a complementação do ensino do estudante.

A Lei $\mathrm{n}^{\mathrm{o}} 11.788 / 2008$, em seu Artigo $1^{\mathrm{o}}$, define estágio como sendo

[...] ato educativo escolar supervisionado, desenvolvido no ambiente de trabalho, que visa à preparação para o trabalho produtivo de educandos que estejam frequentando o ensino regular em instituições de educação superior, de educação profissional, de ensino médio, da educação especial e dos anos finais do ensino fundamental, na modalidade profissional da educação de jovens e adultos (BRASIL, 2008 , texto digital).

Também definiu as modalidades de estágio, podendo este ser obrigatório, cuja carga horária é requisito para aprovação e obtenção de diploma, ou não obrigatório, quando o estágio se trata de atividade opcional, acrescida à carga horária regular e obrigatória do curso. 


\section{ESTÁGIO NÃO OBRIGATÓRIO: CONTRIBUIÇÕES PARA A FORMAÇÃO ACADÊMICA E PROFISSIONAL DO ESTUDANTE DA UNIVATES \\ DOI: http://dx.doi.org/10.5007/1983-4535.2014v7n2p47}

Os principais benefícios proporcionados pela referida lei são a limitação da carga horária diária de estágio; a concessão de bolsa-auxílio e auxílio-transporte; a concessão de recesso remunerado; a determinação do número máximo de estagiários em relação ao quadro de empregados das concedentes; a aplicação de legislação relacionada à saúde e segurança no trabalho; a destinação de $10 \%$ das vagas oferecidas pela empresa concedente às pessoas com necessidades especiais; a duração do tempo de estágio por unidade concedente.

Além dessas alterações, também se tornou necessário o acompanhamento do aluno por professor da Instituição de Ensino e por profissional do quadro de empregados da empresa concedente, com formação ou experiência profissional em área de conhecimento do curso do estagiário, o que reforça o caráter pedagógico dessa atividade. Valverde (2006) afirma que a supervisão é necessária para que se verifique se o estágio de fato é desenvolvido dentro dos padrões acadêmicos, trazendo benefícios de aprendizagem ao estudante. Segundo esse autor, para que o estágio tenha uma adequação didático-pedagógica, necessariamente deve haver uma orientação acadêmica realizada pela instituição de ensino.

A supervisão docente pode ser benéfica também para o professor, pois este pode "aprimorar seus conhecimentos e competências, fazendo a ligação direta do mundo acadêmico com o mundo empresarial, criando assim, condições efetivas de crescimento e desenvolvimento" (TRACZ e DIAS, 2008, p. 12).

\subsection{FORMAÇÃO ACADÊMICA E PROFISSIONAL E A RELAÇÃO TEORIA X PRÁTICA}

A forma e rapidez que se dão as relações profissionais exigem que os profissionais já entrem no mercado de trabalho preparados para desempenharem a sua profissão. Por isso, Souza (1999) entende que a formação deve ter um compromisso com a construção do conhecimento e vida profissional. Para esse autor, a formação profissional deve estar atrelada a determinados aspectos, a saber: agir, pensar, refletir, inovar e recriar. No entanto, o sucesso desse processo depende da articulação entre a teoria e a prática, o conhecimento e a realidade.

Para Teixeira et al. (2010, p.2), o estágio, para o aluno, é

[...] um ensaio, um momento de ascensão na preparação do aluno para sua vida profissional. É por meio do estágio que o aluno, enfrentando os desafios do mundo moderno, tem a possibilidade de aprender fazendo, transformar o saber ao aliar a teoria aprendida na academia com prática utilizada nas organizações. Desta forma, o estágio pode ser considerado um campo de treinamento, um espaço prático de aprendizagem onde ( $\mathrm{sic}$ ) o estudante terá contato com situações e atividades de aprendizagem que visam à formação profissional do mesmo (sic). 


\title{
ESTÁGIO NÃO OBRIGATÓRIO: CONTRIBUIÇÕES PARA A FORMAÇÃO ACADÊMICA E PROFISSIONAL DO ESTUDANTE DA UNIVATES \\ DOI: http://dx.doi.org/10.5007/1983-4535.2014v7n2p47
}

Já Andrade (2004) afirma que o estágio permite a integração da teoria com a prática, do conceitual com o concreto, do virtual com o real.

Verifica-se que o estágio não obrigatório é um elo entre a vida de estudante e o mercado de trabalho, sendo uma espécie de iniciação profissional. O contato com a vida organizacional permite que o estagiário perceba como será a sua futura realidade, identificando o que dele será esperado e como poderá contribuir para o desenvolvimento das organizações. Mas isso, somente se houver relação entre a teoria e a prática.

Sobre a relação teoria-prática, Schwartz (2001, p. 5) salienta que

\begin{abstract}
Embora diferentes, teoria e prática são por natureza inseparáveis, pois é absurda qualquer tentativa de circunscrevê-las em momentos isolados. [...]

A teoria e a prática concebidas como dimensão de um mesmo processo unitário se efetivam, segundo Vasquez, por meio de uma dinâmica em que a teoria orienta a ação, entendida como transformação da realidade, e esta, por sua vez, pode reorientar a própria teoria, fazendo-a avançar e progredir.
\end{abstract}

A partir disso, Schwartz (2001) apresenta um diagrama que demonstra como ocorre a relação teoria x prática durante o estágio. De acordo com a autora, quando a teoria e a prática são trabalhadas em conjunto, permitindo que a primeira seja o ponto de reflexão crítica da realidade, buscando compreendê-la e transformá-la, o estágio torna-se um elo, que resultará em alguma proposta inovadora.

Cabe, no entanto, ressaltar que, para que a experiência prática possa ser aproveitada, é necessário que ela esteja ligada com conhecimentos adquiridos previamente por parte do estudante (WITTMANN; TREVISAN, 2008). Fujino e Vasconselos (2011) complementam lembrando que este princípio pressupõe liberdade e autonomia para o estudante em seus processos de construção de significados, e não apenas uma orientação sobre o que e como fazer.

Além dos benefícios para o estudante, a relação teoria x prática também apresenta vantagem para a instituição de ensino: como o estágio envolve supervisão e correção, pode auxiliar na melhoria do ensino e na revisão de currículos de cursos (Bianchi, Alvarenga, Bianchi, 2001). Almeida, Lagemann e Souza (2006) concordam com essa afirmação ao observarem que os resultados dos relatórios de estágio possibilitam o redirecionamento ou revisão de conteúdos acadêmicos que não possuem aplicabilidade nas organizações. Complementam informando que essa medida não somente permite a formação de profissionais mais preparados, mas, também, a constante oxigenação das estruturas curriculares. 


\section{ESTÁGIO NÃO OBRIGATÓRIO: CONTRIBUIÇÕES PARA A FORMAÇÃO ACADÊMICA E \\ PROFISSIONAL DO ESTUDANTE DA UNIVATES \\ DOI: http://dx.doi.org/10.5007/1983-4535.2014v7n2p47}

\subsection{PONTOS POSITIVOS E NEGATIVOS DO ESTÁGIO NÃO OBRIGATÓRIO}

Wittmann e Trevisan (2008) demonstram as vantagens conseguidas com o estágio por todos os envolvidos nesse processo. Segundo esses autores, para o aluno, o estágio deve servir como um elemento motivador ao estudo, ser um facilitador no processo de assimilação de conteúdos escolares, estimular a criatividade e facilitar a transição da vida estudantil para a profissional. Por outro lado, para a instituição de ensino, o estágio é importante para divulgar a qualidade do ensino da instituição e aperfeiçoar os conteúdos das disciplinas.

Por fim, citam como vantagens para a empresa concedente o espírito de criatividade das novas gerações de estudantes e a redução nos custos de treinamento. Além disso, verificase que o estágio é uma forma estratégica de atrair e reter talentos, desenvolvendo a força de trabalho de acordo com a cultura da empresa sem os altos encargos trabalhistas existentes no Brasil.

O estágio não obrigatório também apresenta benefícios à sociedade mesmo durante o seu desenvolvimento. Vasconcelos (2011) comprova isso ao afirmar que a bolsa-auxílio é um importante recurso financeiro para que muitos alunos de baixa renda possam financiar seus estudos.

O estágio não obrigatório não é, no entanto, constituído apenas por vantagens. Frey e Frey (2002) citam alguns pontos negativos, dos quais se destacam: dificuldade no acesso às informações da empresa; aprofundamento, geralmente, em apenas um assunto do curso; problemas de supervisão; falta de encontros periódicos com o professor supervisor.

Desses, o mais problemático é o que diz respeito à supervisão. As instituições de ensino encontram muitas dificuldades para realizar o acompanhamento do estágio não obrigatório, já que esta atividade demanda recursos humanos e financeiros. Segundo Probst apud Vasconcelos (2011), a universidade tornou-se o elo fraco da corrente, pois é pressionada pelo mercado de trabalho, da justiça do trabalho e dos agentes de integração.

Pode-se verificar que o estágio não obrigatório possui várias facetas. De acordo com Melo (2010, p. 36), “dependendo [...] do enfoque em que se discuta o assunto, podem-se perceber aspectos positivos e negativos envolvidos". No entanto, deve-se considerar que os aspectos positivos certamente se sobrepõem aos negativos, compensando eventuais dificuldades. 


\section{ESTÁGIO NÃO OBRIGATÓRIO: CONTRIBUIÇÕES PARA A FORMAÇÃO ACADÊMICA E \\ PROFISSIONAL DO ESTUDANTE DA UNIVATES \\ DOI: http://dx.doi.org/10.5007/1983-4535.2014v7n2p47}

\section{MÉTODOS}

A presente pesquisa se classificou como um estudo exploratório, pois, segundo Gil (2007, p. 41), a pesquisa exploratória objetiva "proporcionar maior familiaridade com o problema, com vistas a torná-lo mais explícito ou construir hipóteses". Segundo esse autor, esses estudos possuem como principal objetivo o aprimoramento de ideias ou o levantamento de intuições por meio de levantamento bibliográfico e entrevistas com pessoas que tiveram experiências práticas com o problema pesquisado.

Com base nos procedimentos técnicos, este trabalho utilizou a pesquisa bibliográfica e levantamento. A pesquisa bibliográfica buscou material teórico em estudos já publicados sobre o tema, sendo suas fontes livros, periódicos, anais de encontros, teses, dissertações e matérias disponíveis na internet. Já o levantamento se deu por meio da aplicação de questionários às partes envolvidas no contrato de estágio de alunos que realizavam estágio não obrigatório na Univates no mês de novembro de 2012.

O estudo foi realizado a partir da análise de três populações: alunos, professores supervisores e empresas concedentes de estágio não obrigatório. Chegou-se ao tamanho dos grupos por meio de relatório fornecido pelo Núcleo de Estágios da Univates.

A população de alunos compreendeu o total de estudantes da Univates que realizavam estágio não obrigatório no mês de novembro de 2012. Para a amostra, optou-se por entrevistar alunos que estavam estagiando há pelo menos seis meses. Este tempo mínimo de estágio foi necessário para que somente fossem entrevistados alunos com certa vivência com essa modalidade de contratação e com condições de avaliar criticamente as contribuições que ela trouxe para a sua vida acadêmica e profissional. Com isso, a amostra de alunos foi de 508 estudantes.

Já a população de empresas compreendeu todas as concedentes que possuíam alunos da Univates contratados como estagiários, também no mês de novembro de 2012, sendo a mesma regra da amostra dos estagiários aplicada às empresas concedentes, ou seja, somente foram entrevistadas empresas que contavam com estagiários há pelo menos um semestre. Além disso, a amostra foi selecionada de forma não probabilística, por acesso, considerando que a autora não possuía o contato da direção ou setor responsável pelo controle dos estágios não obrigatórios de todas as empresas. Assim, optou-se por entrevistar somente as empresas concedentes que contratavam estagiários diretamente com a Univates, sem a interveniência de agentes de integração, totalizando 46 empresas. 


\section{ESTÁGIO NÃO OBRIGATÓRIO: CONTRIBUIÇÕES PARA A FORMAÇÃO ACADÊMICA E PROFISSIONAL DO ESTUDANTE DA UNIVATES \\ DOI: http://dx.doi.org/10.5007/1983-4535.2014v7n2p47}

Por fim, a população de professores supervisores se constituiu de 60 coordenadores de curso, responsáveis pela supervisão dessa modalidade de estágio no Centro Universitário UNIVATES. A amostra foi composta por 46 professores, considerando que somente foram contatados os cursos que possuíam alunos realizando estágio não obrigatório no mês de novembro de 2012.

Foram elaborados três questionários para a coleta de dados primários, todos baseados na fundamentação teórica estudada: um destinado aos estagiários, o segundo aos professores supervisores e o terceiro às empresas concedentes de estágio não obrigatório. Cada questionário foi constituído de perguntas estruturadas de múltipla escolha e de perguntas não estruturadas. Dessa forma, foi possível coletar respostas para questões específicas do pesquisador e também opiniões e impressões dos entrevistados sobre o tema estudado.

A coleta de dados aconteceu no mês de novembro de 2012, tendo a aplicação do questionário ocorrido através de formulário eletrônico do Google Docs. Após, os dados foram tratados em planilha eletrônica, o que possibilitou a criação de gráficos e tabelas para a melhor análise de resultados obtidos.

\section{RESULTADOS}

Dos 508 alunos convidados a responder o questionário, apenas 79 o responderam, representando $15,55 \%$ do total. Em relação aos professores supervisores, 14 participaram da coleta de dados, representando $30,43 \%$ do grupo convidado. Já o questionário das empresas concedentes foi respondido por 11 contratantes, o que equivale a 23,91\% das empresas que contemplavam os critérios estabelecidos.

Dessa forma, cabe salientar que os dados não representam a opinião da população pesquisada, mas somente dos respondentes da pesquisa.

\subsection{PERFIL DOS RESPONDENTES}

Primeiramente, constatou-se que $77 \%$ dos estudantes respondentes são do sexo feminino e apenas $23 \%$ são do sexo masculino.

Em relação à faixa etária, $76 \%$ dos estagiários possuem até 24 anos, ou seja, a maioria dos estudantes em estágio não obrigatório são jovens que estão iniciando a vida profissional. Quinze por cento possui de 25 a 28 anos, 4\% de 29 a 32 anos e 5\% possui 33 anos ou mais. 


\section{ESTÁGIO NÃO OBRIGATÓRIO: CONTRIBUIÇÕES PARA A FORMAÇÃO ACADÊMICA E PROFISSIONAL DO ESTUDANTE DA UNIVATES \\ DOI: http://dx.doi.org/10.5007/1983-4535.2014v7n2p47}

O questionário destinado aos professores supervisores buscou identificar a forma utilizada para realizar a supervisão dos alunos estagiários pela Univates, tendo todos os professores respondido que utilizam o relatório como forma de supervisão. Este dado vem ao encontro das atividades do Núcleo de Estágios da Univates, que exige do aluno a apresentação periódica do relatório para a permanência no estágio não obrigatório.

As demais formas de acompanhamento citadas pelos professores foram conversas informais com alunos ou empresas, e-mail e, por fim, telefonemas, tendo apenas um professor indicado realizar visitas ao campo de estágio para acompanhamento in loco. Verificou-se que os professores possuem pouco contato com os estudantes durante a supervisão das atividades, o que pode ser descrito como um ponto fraco da Univates em relação aos estágios não obrigatórios.

O questionário destinado às empresas buscou identificar o perfil das concedentes de estágio não obrigatório aos alunos da Univates, bem como as suas políticas de administração dessa modalidade de contratação.

Primeiramente, buscou-se identificar o tempo de existência dessas empresas. Constatou-se que $64 \%$ atuam no mercado há 10 anos ou mais, $18 \%$ possuem até três anos e outras $18 \%$ de quatro a seis anos.

Constatou-se também que a grande maioria das empresas concedentes possui até três estagiários contratados, subentendendo-se que são empresas de pequeno porte. Somente $9 \%$ responderam cada um dos demais itens possíveis, indicando que poucas concedentes possuem mais de quatro estagiários. Em complemento ao tempo de existência das organizações, percebeu-se que os respondentes da pesquisa são empresas já estabelecidas em sua atividade, por terem 10 anos ou mais de atuação, mas de pequeno porte, por terem poucos estagiários contratados.

Em seguida, as empresas foram questionadas sobre a possibilidade de efetivação dos estagiários, tendo $82 \%$ respondido que os estudantes têm possibilidade de serem efetivados após o término do contrato. No entanto, $73 \%$ delas indicaram que apenas $20 \%$ dos estudantes são efetivados. Este resultado é, de certa forma, incoerente. Pode-se entender que os alunos não possuem interesse em permanecer na empresa e, por isso, o índice de efetivação é baixo, mesmo que a empresa almeje manter o estudante após o término do contrato. 


\section{ESTÁGIO NÃO OBRIGATÓRIO: CONTRIBUIÇÕES PARA A FORMAÇÃO ACADÊMICA E \\ PROFISSIONAL DO ESTUDANTE DA UNIVATES \\ DOI: http://dx.doi.org/10.5007/1983-4535.2014v7n2p47}

\subsection{ESTÁGIO NÃO OBRIGATÓRIO, FORMAÇÃO ACADÊMICA E PROFISSIONAL E MERCADO DE TRABALHO}

Durante a pesquisa, os três grupos foram questionados se as atividades realizadas no estágio não obrigatório estão de acordo com a área de formação dos estudantes. Verificou-se que as respostas se equiparam e que a grande maioria considera que as atividades realizadas são compatíveis com a área de formação, já que $88 \%$ dos estagiários, $100 \%$ dos professores supervisores e $86 \%$ das empresas concedentes concordaram ou concordaram totalmente com a afirmação. Apenas 3\% dos alunos e 9\% das empresas discordaram.

Ao serem questionados se as atividades realizadas no estágio não obrigatório complementam o aprendizado que os alunos recebem no curso, verificou-se que $90 \%$ dos alunos, $86 \%$ dos professores supervisores e 100\% das empresas concordam ou concordam totalmente com a afirmação. Apenas $9 \%$ dos alunos e 14\% dos professores não concordam nem discordam, e somente $3 \%$ dos estudantes discordam da afirmação.

A contribuição do estágio não obrigatório para a formação acadêmica dos estudantes também foi bem avaliada, já que $95 \%$ dos alunos, $72 \%$ dos professores e $91 \%$ das empresas consideram que o estágio tem boa ou ótima contribuição, o que pode demonstrar que as atividades desenvolvidas pelos estagiários realmente estão de acordo com a sua área de formação. Destacou-se que apenas professores supervisores consideram a contribuição péssima ou ruim, totalizando $14 \%$ dos respondentes.

O mesmo ocorreu ao responderem sobre a contribuição do estágio não obrigatório para a formação profissional dos estudantes: $96 \%$ dos alunos, $79 \%$ dos professores e $91 \%$ das empresas consideram que o estágio tem boa ou ótima contribuição. Nesse sentido, apenas professores consideraram a contribuição ruim, totalizando $7 \%$ dos respondentes. Isso demonstrou que o estágio não obrigatório permite aos alunos vivenciar a realidade do mercado de trabalho ou de sua futura profissão, preparando-os para a vida profissional.

Em complemento a essa questão, os grupos foram questionados se o estágio não obrigatório possibilita reflexão sobre a futura profissão e contribui para que o aluno repense a escolha profissional. Oitenta e cinco por cento dos alunos, $78 \%$ dos professores e $91 \%$ das empresas concordaram. No entanto, $7 \%$ dos professores discordaram totalmente, $5 \%$ dos estagiários discordaram e todos os grupos foram representados na opção "Não concordo e nem discordo", o que levou a crer que os respondentes não tratam o estágio como uma atividade pedagógica para a formação acadêmica e profissional do aluno. 


\section{ESTÁGIO NÃO OBRIGATÓRIO: CONTRIBUIÇÕES PARA A FORMAÇÃO ACADÊMICA E \\ PROFISSIONAL DO ESTUDANTE DA UNIVATES \\ DOI: http://dx.doi.org/10.5007/1983-4535.2014v7n2p47}

Quanto à reprodução do mercado de trabalho, a maioria dos entrevistados de cada grupo acredita que o estágio não obrigatório permite ao estudante vivenciar essa realidade ( $85 \%$ dos estagiários, $86 \%$ dos professores e 91\% das empresas). Esse resultado é importante para confirmar que o estágio não obrigatório pode ser um meio de preparação para o mercado de trabalho no qual o estudante pode desenvolver suas atividades de forma segura após formado.

Os grupos foram questionados sobre a qualidade da supervisão despendida aos estudantes. O Gráfico 1 demonstra que a opinião dos grupos sobre a supervisão da Univates é semelhante. A maioria concorda que ela é suficiente, mas muitos respondentes discordam totalmente, discordam ou não concordam e nem discordam, demonstrando uma fragilidade da Univates em relação aos estágios não obrigatórios.

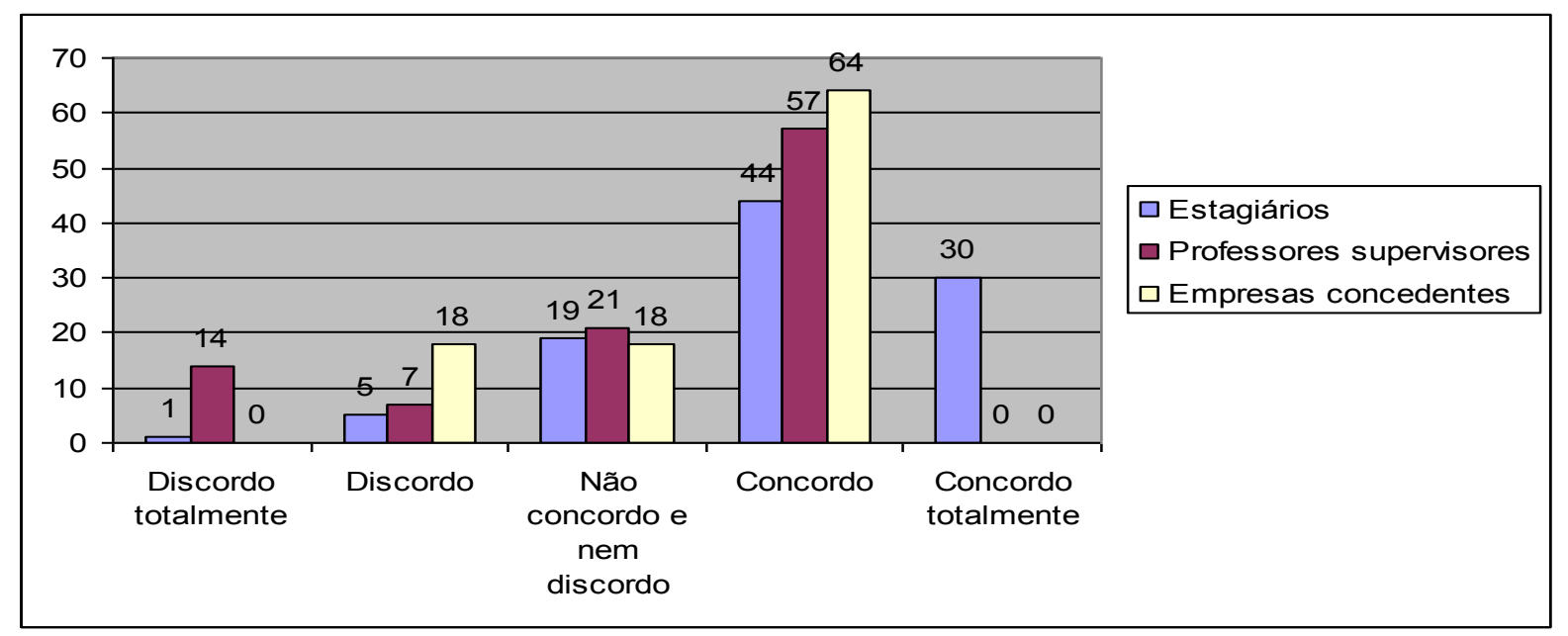

Gráfico 1 Percepção dos participantes quanto à supervisão da Univates (\%)

Fonte: Elaborado pelas autoras conforme dados levantados no estudo.

Já o Gráfico 2 mostra que as respostas dos grupos em relação à supervisão da empresa são muito parecidas com o considerado sobre a supervisão da Univates: muitos a consideram suficiente, mas há respostas que discordam. Isso demonstrou que nem todos os estagiários recebem o acompanhamento exigido em lei, podendo ser tratados como funcionários e não como acadêmicos aprendizes. 


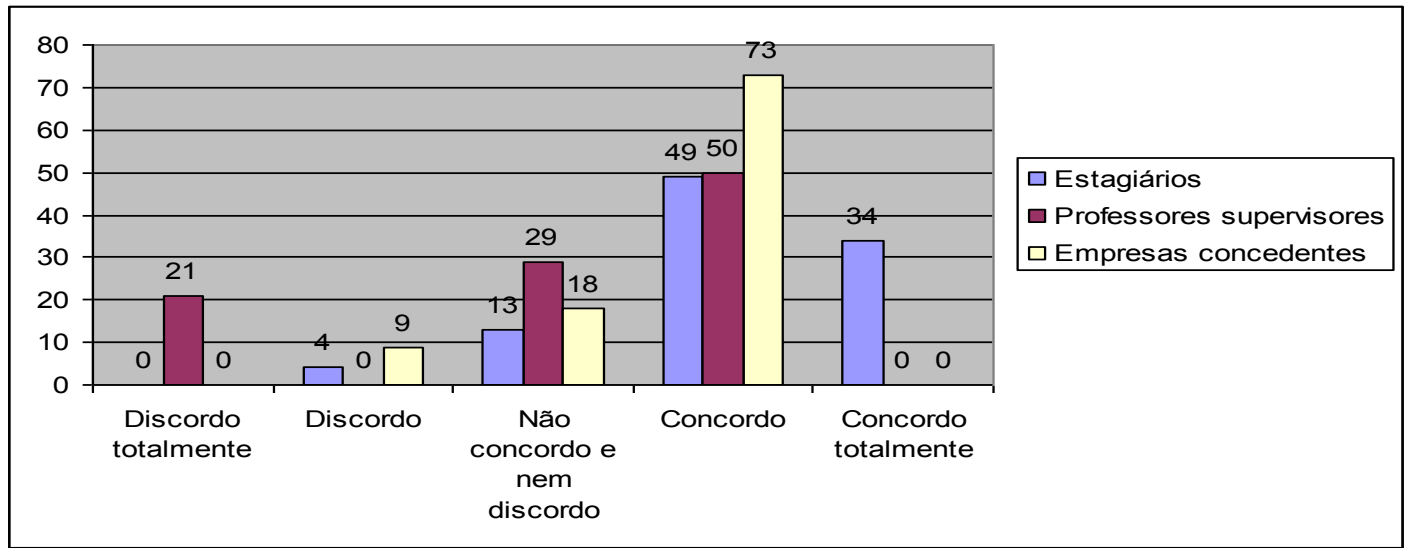

Gráfico 2 Percepção dos pesquisados quanto à supervisão da empresa concedente (\%) Fonte: Elaborado pelas autoras conforme dados levantados no estudo.

\subsection{IMPACTOS DO ESTÁGIO NÃO OBRIGATÓRIO PARA O DESEMPENHO ACADÊMICO E PROFISSIONAL E PARA O MERCADO DE TRABALHADO}

Após avaliação da relação do estágio não obrigatório com o desempenho acadêmico dos estudantes, verificou-se, conforme a Tabela 1, que todos os grupos consideram que o estágio não atrapalha o desempenho acadêmico dos alunos e que permite maior assimilação dos conteúdos estudados no curso, bem como proporciona visão mais clara da teoria nele apresentada.

Tabela 1 Relação do estágio não obrigatório com o desempenho acadêmico

\begin{tabular}{|c|c|c|c|c|c|c|}
\hline \multicolumn{2}{|c|}{ Grupos/Respostas } & $\begin{array}{c}\text { Atrapalha o } \\
\text { desempenho } \\
\text { acadêmico } \\
(\%)\end{array}$ & $\begin{array}{c}\text { Diminui o } \\
\text { tempo } \\
\text { destinado } \\
\text { aos } \\
\text { estudos } \\
(\%)\end{array}$ & $\begin{array}{l}\text { Permite } \\
\text { maior } \\
\text { assimilaçã } \\
\quad \text { o de } \\
\text { conteúdos } \\
\text { estudados } \\
\quad(\%) \\
\end{array}$ & $\begin{array}{c}\text { Proporcion } \\
\text { a visão mais } \\
\text { clara da } \\
\text { teoria } \\
\text { apresentada } \\
\text { no curso } \\
(\%) \\
\end{array}$ & $\begin{array}{c}\text { Aumenta } \\
\text { o interesse } \\
\text { pelo curso } \\
\text { (\%) }\end{array}$ \\
\hline \multirow{5}{*}{ Estagiários } & Discordo totalmente & 48 & 30 & 1 & 1 & 0 \\
\hline & Discordo & 41 & 25 & 5 & 6 & 8 \\
\hline & $\begin{array}{l}\text { Não concordo e nem } \\
\text { discordo }\end{array}$ & 6 & 18 & 14 & 8 & 13 \\
\hline & Concordo & 5 & 22 & 39 & 38 & 38 \\
\hline & Concordo totalmente & 0 & 5 & 41 & 47 & 41 \\
\hline \multirow{5}{*}{$\begin{array}{l}\text { Professores } \\
\text { supervisores }\end{array}$} & Discordo totalmente & 57 & 29 & 0 & 7 & 14 \\
\hline & Discordo & 36 & 36 & 0 & 7 & 0 \\
\hline & $\begin{array}{l}\text { Não concordo e nem } \\
\text { discordo }\end{array}$ & 7 & 21 & 21 & 14 & 14 \\
\hline & Concordo & 0 & 14 & 43 & 43 & 43 \\
\hline & Concordo totalmente & 0 & 0 & 36 & 29 & 29 \\
\hline \multirow{5}{*}{$\begin{array}{c}\text { Empresas } \\
\text { concedentes }\end{array}$} & Discordo totalmente & 73 & 46 & 0 & 9 & 9 \\
\hline & Discordo & 18 & 27 & 9 & 9 & 9 \\
\hline & $\begin{array}{l}\text { Não concordo e nem } \\
\text { discordo }\end{array}$ & 0 & 27 & 0 & 9 & 18 \\
\hline & Concordo & 0 & 0 & 36 & 18 & 37 \\
\hline & Concordo totalmente & 9 & 0 & 55 & 55 & 27 \\
\hline
\end{tabular}

Fonte: Elaborado pelas autoras conforme dados levantados no estudo. 


\section{ESTÁGIO NÃO OBRIGATÓRIO: CONTRIBUIÇÕES PARA A FORMAÇÃO ACADÊMICA E PROFISSIONAL DO ESTUDANTE DA UNIVATES \\ DOI: http://dx.doi.org/10.5007/1983-4535.2014v7n2p47}

Quanto à importância do estágio não obrigatório para o desenvolvimento de competências e habilidades profissionais, os estagiários o consideram muito importante para o desenvolvimento de responsabilidade, postura profissional, relacionamento interpessoal, organização e trabalho em equipe. As competências mais indicadas como sendo sem importância foram o desenvolvimento do espírito empreendedor, liderança, criatividade e raciocínio lógico. Isso pode ser explicado pelo fato de o estagiário ser um auxiliar e aprendiz, não tendo oportunidade de desenvolver atividades que requeiram essas competências durante o estágio não obrigatório. A Tabela 2 descreve a opinião dos grupos entrevistados em relação à importância do estágio não obrigatório para o desenvolvimento de competências, habilidades ou atitudes, demonstrando quais são consideradas Sem Importância (SI), Pouco Importante (PI), Importante (I) ou Muito Importante (MI).

Tabela 2 Importância do estágio não obrigatório para o desenvolvimento de competências, habilidades ou atitudes

\begin{tabular}{|c|c|c|c|c|c|c|c|c|c|c|c|c|}
\hline \multirow[t]{2}{*}{$\begin{array}{c}\text { Competências e } \\
\text { habilidades }\end{array}$} & \multicolumn{4}{|c|}{ Estagiários } & \multicolumn{4}{|c|}{$\begin{array}{l}\text { Professores } \\
\text { supervisores }\end{array}$} & \multicolumn{4}{|c|}{ Empresas concedentes } \\
\hline & $\begin{array}{c}\text { SI } \\
(\%)\end{array}$ & $\begin{array}{l}\text { PI } \\
(\%)\end{array}$ & $\begin{array}{c}\text { I } \\
(\%)\end{array}$ & $\begin{array}{l}\text { MI } \\
(\%)\end{array}$ & $\begin{array}{c}\text { SI } \\
(\%)\end{array}$ & $\begin{array}{l}\text { PI } \\
(\%)\end{array}$ & $\begin{array}{c}\text { I } \\
(\%)\end{array}$ & $\begin{array}{l}\text { MI } \\
(\%)\end{array}$ & $\begin{array}{c}\text { SI } \\
(\%)\end{array}$ & $\begin{array}{l}\text { PI } \\
(\%)\end{array}$ & $\begin{array}{c}\mathrm{I} \\
(\%)\end{array}$ & $\begin{array}{l}\mathrm{MI} \\
(\%)\end{array}$ \\
\hline Administração do tempo & 1 & 9 & 56 & 34 & 0 & 14 & 50 & 36 & 9 & 0 & 64 & 27 \\
\hline Capacidade crítica & 1 & 5 & 56 & 38 & 7 & 7 & 50 & 36 & 0 & 0 & 55 & 45 \\
\hline Comunicação oral & 0 & 4 & 44 & 52 & 0 & 14 & 57 & 29 & 0 & 0 & 64 & 36 \\
\hline Comunicação escrita & 0 & 8 & 51 & 41 & 7 & 36 & 36 & 21 & 0 & 0 & 64 & 36 \\
\hline Criatividade & 4 & 5 & 50 & 41 & 7 & 14 & 50 & 29 & 0 & 9 & 36 & 55 \\
\hline Espírito empreendedor & 6 & 22 & 52 & 20 & 7 & 14 & 58 & 21 & 0 & 18 & 45 & 37 \\
\hline Ética & 0 & 1 & 38 & 61 & 0 & 36 & 28 & 36 & 0 & 0 & 27 & 73 \\
\hline Liderança & 5 & 13 & 41 & 41 & 7 & 14 & 58 & 21 & 0 & 18 & 64 & 18 \\
\hline Organização & 1 & 1 & 34 & 64 & 0 & 7 & 57 & 36 & 0 & 0 & 27 & 73 \\
\hline Postura profissional & 1 & 1 & 33 & 65 & 0 & 7 & 43 & 50 & 0 & 0 & 36 & 64 \\
\hline Pro atividade & 0 & 9 & 41 & 50 & 0 & 21 & 50 & 29 & 0 & 0 & 45 & 55 \\
\hline Raciocínio lógico & 4 & 9 & 43 & 44 & 0 & 36 & 36 & 28 & 0 & 0 & 55 & 45 \\
\hline $\begin{array}{l}\text { Relacionamento } \\
\text { interpessoal }\end{array}$ & 1 & 0 & 37 & 62 & 0 & 7 & 43 & 50 & 0 & 0 & 55 & 45 \\
\hline Responsabilidade & 0 & 0 & 32 & 68 & 0 & 14 & 43 & 43 & 0 & 0 & 27 & 73 \\
\hline Senso de hierarquia & 4 & 9 & 45 & 42 & 0 & 7 & 57 & 36 & 0 & 0 & 55 & 45 \\
\hline Trabalho em equipe & 1 & 5 & 32 & 62 & 0 & 7 & 36 & 57 & 0 & 0 & 36 & 64 \\
\hline
\end{tabular}

Fonte: Elaborada pelas autoras conforme dados levantados no estudo.

Uma das perguntas destinadas a identificar a política das empresas em relação ao estágio não obrigatório é o motivo que as leva a contratar estagiários. Oitenta e dois por cento dos respondentes demonstraram estar interessados em desenvolver e formar pessoal internamente. Seguidas de menor custo (73\%) e mão de obra qualificada (55\%), as respostas indicaram que o estágio é considerado um meio de formar bons profissionais a um baixo 


\section{ESTÁGIO NÃO OBRIGATÓRIO: CONTRIBUIÇÕES PARA A FORMAÇÃO ACADÊMICA E PROFISSIONAL DO ESTUDANTE DA UNIVATES \\ DOI: http://dx.doi.org/10.5007/1983-4535.2014v7n2p47}

custo. Nessa questão, o somatório de percentual pode ultrapassar $100 \%$, já que mais de uma opção podia ser selecionada.

Ao receber alguns itens para avaliar a importância de cada um ao procurar um estágio não obrigatório, verificou-se, na Tabela 3, que os itens mais citados remetem ao mercado de trabalho, demonstrando o interesse dos estudantes em procurar o estágio como atividade profissional.

Tabela 3 Grau de importância de cada item para a procura do estágio não obrigatório

\begin{tabular}{l|c|c|c|c}
\hline \multicolumn{1}{c|}{ Item } & $\begin{array}{c}\text { Sem } \\
\text { importância } \\
(\mathbf{\%})\end{array}$ & $\begin{array}{c}\text { Pouco } \\
\text { importante } \\
(\mathbf{\%})\end{array}$ & $\begin{array}{c}\text { Importante } \\
\mathbf{( \% )}\end{array}$ & $\begin{array}{c}\text { Muito } \\
\text { importante } \\
(\mathbf{\%})\end{array}$ \\
\hline Adquirir experiência profissional & 0 & 3 & 10 & 87 \\
Conhecer na prática a área de formação & 1 & 3 & 15 & 81 \\
Adquirir novos conhecimentos & 0 & 1 & 20 & 79 \\
Desenvolver habilidades ou competências & 0 & 1 & 23 & 76 \\
profissionais & 0 & 6 & 18 & 76 \\
Melhorar o currículo & 1 & 8 & 29 & 62 \\
Entrar no mercado de trabalho & 6 & 16 & 41 & 37 \\
Possibilidade de efetivação futura & 23 & 16 & 29 & 32 \\
Repensar a área de formação escolhida & 5 & 25 & 43 & 27 \\
Necessidade financeira & & & & \\
\hline
\end{tabular}

Fonte: Elaborada pelas autoras conforme dados levantados no estudo.

Também foi solicitado aos três grupos entrevistados que descrevessem as dificuldades que encontram no estágio não obrigatório, conforme demonstrado no Quadro 1. Constatou-se que a maior dificuldade dos estagiários é a baixa remuneração paga pela empresa para o desenvolvimento das atividades, seguida da falta de tempo para estudar e do pouco conhecimento teórico ao iniciar o estágio.

Já os professores destacam como maior dificuldade o acompanhamento dos alunos no campo de estágio não obrigatório, uma vez que não possuem destinação de horas para tal atividade. Cabe ressaltar que, de acordo com a Lei $\mathrm{n}^{\circ} 11.788$, de 25 de setembro de 2008, o acompanhamento do estágio pelo professor se dá por meio de vistos em relatórios, o que é cumprido pela Univates.

Em relação às empresas, verificou-se que a maior dificuldade está no comportamento dos estagiários, considerando que como principal dificuldade foi citado o comprometimento dos alunos, além da falta de interesse, de pró-atividade e de pontualidade dos estudantes. 


\section{ESTÁGIO NÃO OBRIGATÓRIO: CONTRIBUIÇÕES PARA A FORMAÇÃO ACADÊMICA E PROFISSIONAL DO ESTUDANTE DA UNIVATES \\ DOI: http://dx.doi.org/10.5007/1983-4535.2014v7n2p47}

\begin{tabular}{|c|c|c|c|c|c|}
\hline \multicolumn{2}{|l|}{ Estagiários } & \multicolumn{2}{|l|}{ Professores supervisores } & \multicolumn{2}{|l|}{ Empresas concedentes } \\
\hline Sem dificuldades & 18 & $\begin{array}{l}\text { Acompanhamento dos alunos no } \\
\text { campo de estágio pela Univates }\end{array}$ & 10 & $\begin{array}{l}\text { Comprometimento dos } \\
\text { estudantes }\end{array}$ & 5 \\
\hline Baixa remuneração & 10 & Poucos campos de estágio & 3 & $\begin{array}{l}\text { Adaptação aos horários } \\
\text { dos estagiários }\end{array}$ & 2 \\
\hline Falta de tempo para estudar & 7 & $\begin{array}{l}\text { Adequar as atividades realizadas } \\
\text { na empresa com o curso }\end{array}$ & 2 & Alta rotatividade & 2 \\
\hline Não responderam & 5 & Comprometimento dos estudantes & 2 & $\begin{array}{l}\text { Falta de interesse em } \\
\text { aprender }\end{array}$ & 2 \\
\hline $\begin{array}{l}\text { Pouco conhecimento } \\
\text { teórico ao iniciar o estágio }\end{array}$ & 5 & $\begin{array}{l}\text { Acompanhamento dos alunos } \\
\text { pelos supervisores da empresa }\end{array}$ & 1 & $\begin{array}{l}\text { Adequar as atividades na } \\
\text { empresa com o curso }\end{array}$ & 1 \\
\hline $\begin{array}{l}\text { Adaptação à rotina dos } \\
\text { processos }\end{array}$ & 3 & $\begin{array}{l}\text { Algumas atividades não são } \\
\text { relacionadas ao curso }\end{array}$ & 1 & Baixa remuneração & 1 \\
\hline $\begin{array}{l}\text { Disponibilidade de material } \\
\text { para realização das tarefas }\end{array}$ & 3 & $\begin{array}{l}\text { Baixa carga horária diária } \\
\text { permitida }\end{array}$ & 1 & $\begin{array}{l}\text { Falta de orientação sobre } \\
\text { documentos }\end{array}$ & 1 \\
\hline Estagiário não é valorizado & 3 & $\begin{array}{lccc}\text { Empresas } & \text { não } & \text { consideram } & \text { o } \\
\text { estágio como } & \text { forma } & \text { de } \\
\text { aprendizado } & & \end{array}$ & 1 & $\begin{array}{l}\text { Falta de pró-atividade dos } \\
\text { estagiários }\end{array}$ & 1 \\
\hline $\begin{array}{l}\text { Muita responsabilidade } \\
\text { repassada para o estagiário }\end{array}$ & 3 & $\begin{array}{l}\text { Estagiário é considerado mão de } \\
\text { obra barata }\end{array}$ & 1 & $\begin{array}{l}\text { Falta de pontualidade dos } \\
\text { estagiários }\end{array}$ & 1 \\
\hline Sem direitos trabalhistas & 3 & $\begin{array}{l}\text { O aluno se dedica mais ao estágio } \\
\text { do que às aulas }\end{array}$ & 1 & $\begin{array}{l}\text { Pouco conhecimento da } \\
\text { área por parte dos } \\
\text { estagiários }\end{array}$ & 1 \\
\hline $\begin{array}{l}\text { Acompanhamento } \quad \mathrm{da} \\
\text { empresa }\end{array}$ & 2 & $\begin{array}{l}\text { Período de dois anos para realizar } \\
\text { estágio é muito longo }\end{array}$ & 1 & $\begin{array}{l}\text { Pouco conhecimento } \\
\text { teórico ao iniciar o estágio }\end{array}$ & 1 \\
\hline Burocracia & 2 & $\begin{array}{l}\text { Possibilidade de desvirtuar as } \\
\text { funções do estagiário }\end{array}$ & 1 & Sem dificuldades & 1 \\
\hline $\begin{array}{l}\text { Dificuldade no } \\
\text { entendimento das tarefas }\end{array}$ & 2 & $\begin{array}{l}\text { Qualificação dos profissionais } \\
\text { supervisores }\end{array}$ & 1 & & \\
\hline $\begin{array}{l}\text { Pouca flexibilidade de } \\
\text { horários }\end{array}$ & 2 & $\begin{array}{l}\text { Requisitos para iniciar o estágio } \\
\text { (disciplinas) }\end{array}$ & 1 & & \\
\hline $\begin{array}{l}\text { Aproveitamento de poucas } \\
\text { horas como atividade } \\
\text { complementar }\end{array}$ & 2 & & & & \\
\hline $\begin{array}{l}\text { Sem possibilidade de } \\
\text { efetivação }\end{array}$ & 2 & & & & \\
\hline
\end{tabular}

Quadro 1 Dificuldades encontradas no estágio não obrigatório e número de citações

Fonte: Elaborada pelas autoras conforme dados levantados no estudo.

Os grupos entrevistados também foram questionados sobre os benefícios do estágio não obrigatório, descrevendo duas vantagens encontradas nesta modalidade de contratação. Notou-se, no Quadro 2, que, para os estudantes, a maior vantagem do estágio não obrigatório é adquirir conhecimentos na área de formação, seguido da oportunidade de conciliar teoria e prática e de adquirir experiência profissional.

Para os professores supervisores, a oportunidade de conciliar teoria e prática também foi citada como um benefício, juntamente com a oportunidade de inserção no mercado de trabalho. 


\section{ESTÁGIO NÃO OBRIGATÓRIO: CONTRIBUIÇÕES PARA A FORMAÇÃO ACADÊMICA E PROFISSIONAL DO ESTUDANTE DA UNIVATES \\ DOI: http://dx.doi.org/10.5007/1983-4535.2014v7n2p47}

Por fim, a oportunidade de conciliar teoria e prática foi o benefício mais lembrado também pelas empresas concedentes, seguido de menor custo de contratação e da oportunidade de adquirir conhecimentos sobre a futura profissão.

\begin{tabular}{|c|c|c|c|c|c|}
\hline \multicolumn{2}{|l|}{ Estagiários } & \multicolumn{2}{|l|}{ Professores supervisores } & \multicolumn{2}{|l|}{ Empresas concedentes } \\
\hline $\begin{array}{l}\text { Conhecimentos na área de } \\
\text { formação }\end{array}$ & 29 & Conciliar teoria e prática & 5 & Conciliar teoria e prática & 4 \\
\hline Conciliar teoria e prática & 16 & Inserção no mercado de trabalho & 5 & Menor custo & 3 \\
\hline Experiência profissional & 14 & $\begin{array}{l}\text { Adquirir conhecimentos sobre a } \\
\text { futura profissão }\end{array}$ & 4 & $\begin{array}{l}\text { Adquirir conhecimentos sobre a } \\
\text { futura profissão }\end{array}$ & 2 \\
\hline Melhorar o currículo & 7 & $\begin{array}{l}\text { Conhecer a realidade } \text { do } \\
\text { mercado de trabalho }\end{array}$ & 2 & $\begin{array}{l}\text { Formação de mão de obra } \\
\text { qualificada }\end{array}$ & 2 \\
\hline Oportunidade de renda & 6 & Amadurecimento do aluno & 1 & Aperfeiçoamento profissional & 1 \\
\hline $\begin{array}{l}\text { Confirmar/repensar } \\
\text { profissão escolhida }\end{array}$ & 5 & $\begin{array}{l}\text { Capacitação para relações } \\
\text { paciente/profissional }\end{array}$ & 1 & $\begin{array}{l}\text { Conhecer a realidade do } \\
\text { mercado de trabalho }\end{array}$ & 1 \\
\hline $\begin{array}{l}\text { Conhecer a realidade do } \\
\text { mercado de trabalho }\end{array}$ & 5 & $\begin{array}{l}\text { Confirmar ou repensar } \\
\text { profissão escolhida }\end{array}$ & 1 & $\begin{array}{l}\text { Conhecer diversas áreas do } \\
\text { curso }\end{array}$ & 1 \\
\hline Crescimento profissional & 5 & $\begin{array}{l}\text { Confronto com realidades não } \\
\text { disponibilizadas pela academia }\end{array}$ & 1 & $\begin{array}{l}\text { Conhecer o profissional antes } \\
\text { de contratá-lo }\end{array}$ & 1 \\
\hline Flexibilidade de horários & 5 & 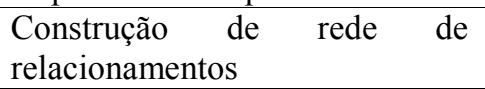 & 1 & $\begin{array}{l}\text { Contratação imediata, } \\
\text { necessidade de concurso }\end{array}$ & 1 \\
\hline Não responderam & 5 & $\begin{array}{l}\text { Desenvolvimento de habilidades } \\
\text { e competências }\end{array}$ & 1 & $\begin{array}{lrr}\begin{array}{l}\text { Contribuir } \\
\text { aperfeiçoamento }\end{array} & \text { para } & \text { o } \\
\text { profissional } & & \text { um } \\
\end{array}$ & 1 \\
\hline $\begin{array}{l}\text { Adquirir conhecimentos } \\
\text { não obtidos na graduação }\end{array}$ & 4 & Divulga o curso & 1 & $\begin{array}{l}\text { Formar o profissional de acordo } \\
\text { com as necessidades da empresa }\end{array}$ & 1 \\
\hline Maior tempo para estudos & 4 & Divulga o profissional & 1 & $\begin{array}{lrr}\text { Introdução } & \text { de } & \text { novas } \\
\text { ferramentas na } & \text { empresa, } \\
\text { trazidas pelo aluno } & \end{array}$ & 1 \\
\hline $\begin{array}{l}\text { Adquirir conhecimentos } \\
\text { sobre a futura profissão }\end{array}$ & 3 & $\begin{array}{l}\text { Experiências para discussões em } \\
\text { sala de aula }\end{array}$ & 1 & $\begin{array}{l}\text { Troca de conhecimentos entre } \\
\text { empresa e aluno }\end{array}$ & 1 \\
\hline $\begin{array}{l}\text { Convívio com profíssionais } \\
\text { já formados }\end{array}$ & 3 & $\begin{array}{l}\text { Não consegue identificar por } \\
\text { falta de acompanhamento }\end{array}$ & 1 & & \\
\hline Possibilidade de efetivação & 3 & $\begin{array}{l}\text { Oportunidade de conhecimento } \\
\text { de ferramentas de gestão }\end{array}$ & 1 & & \\
\hline $\begin{array}{l}\text { Aprender a lidar com o } \\
\text { público }\end{array}$ & 2 & Possibilidade de efetivação & 1 & & \\
\hline Aprendizado constante & 2 & & & & \\
\hline $\begin{array}{l}\text { Desenvolvimento das } \\
\text { habilidades e competências }\end{array}$ & 2 & & & & \\
\hline $\begin{array}{l}\text { Facilita a aprendizagem em } \\
\text { sala de aula }\end{array}$ & 2 & & & & \\
\hline $\begin{array}{l}\text { Melhora } \mathrm{o} \text { trabalho } \mathrm{em} \\
\text { equipe }\end{array}$ & 2 & & & & \\
\hline
\end{tabular}

Quadro 2 Benefícios encontrados no estágio não obrigatório e número de citações

Fonte: Elaborada pelas autoras conforme dados levantados no estudo.

Verificou-se que o estágio não obrigatório para os alunos da Univates é um processo de aprendizagem profissional, mas com características específicas, conforme relaciona a 


\section{ESTÁGIO NÃO OBRIGATÓRIO: CONTRIBUIÇÕES PARA A FORMAÇÃO ACADÊMICA E \\ PROFISSIONAL DO ESTUDANTE DA UNIVATES \\ DOI: http://dx.doi.org/10.5007/1983-4535.2014v7n2p47}

teoria apresentada. Apesar da dificuldade de supervisão, professores e empresas concedentes possibilitam ao estudante desenvolver competências e habilidades que serão importantes para o seu futuro profissional, além de desenvolver atividades na futura área de formação, tornando o estágio não obrigatório um elo entre o estudante e o futuro trabalhador.

\section{CONCLUSÃO}

De maneira geral, é possível afirmar que a percepção sobre a contribuição do estágio não obrigatório é positiva para os três grupos participantes e que todos alcançam os objetivos buscados com a prática dessa modalidade de estágio. De acordo com a pesquisa, o estágio não obrigatório possibilita aos estudantes a aplicação prática dos conhecimentos adquiridos durante o curso e a obtenção de experiências úteis ao futuro profissional. Isso faz com que essa atividade seja uma forma de complementar o ensino adquirido durante o curso, possibilitando que o estudante reflita sobre a escolha profissional e a rotina de sua futura carreira.

A reprodução da realidade do mercado de trabalho também é facilitada pelo estágio não obrigatório, fazendo com que ele traga diversas contribuições para a vida dos estudantes. A vivência da profissão proporciona ao educando desenvolver diversas competências e habilidades exigidas pela profissão, aproximando-o do mercado de trabalho e fazendo com que ele esteja preparado para assumir as suas funções como profissional após a graduação.

De acordo com os estudantes, adquirir experiência profissional, melhorar o currículo, desenvolver habilidades e competências, adquirir novos conhecimentos e conhecer na prática a área de formação escolhida são motivos importantes para procurar um estágio não obrigatório. É possível observar que a maioria dessas razões possui relação com o mercado de trabalho, sendo este mais um motivo da importância do estágio não obrigatório para a formação profissional desses educandos. Por outro lado, a necessidade financeira também é apresentada como um motivo importante, demonstrando a necessidade da bolsa auxílio para a permanência na universidade. Por isso, cabe à Univates continuar estimulando os seus alunos a procurarem vagas de estágio não obrigatório por meio da divulgação de oportunidades encaminhadas por empresas.

Já as empresas consideram importante conceder vagas de estágio não obrigatório, principalmente para formar os profissionais internamente. Aliado a isso, aparece o baixo custo e a oportunidade de contratar mão de obra qualificada. Dessa forma, verifica-se que as 


\section{ESTÁGIO NÃO OBRIGATÓRIO: CONTRIBUIÇÕES PARA A FORMAÇÃO ACADÊMICA E PROFISSIONAL DO ESTUDANTE DA UNIVATES \\ DOI: http://dx.doi.org/10.5007/1983-4535.2014v7n2p47}

empresas participantes concordam com a teoria apresentada: o estágio não obrigatório não é apenas uma forma de aprendizado ao aluno, mas, também, uma forma de recrutamento para as organizações, que forma o profissional de acordo com as suas necessidades e sem os encargos trabalhistas impostos pela legislação brasileira.

A pesquisa, contudo, também evidencia problemas em relação ao estágio não obrigatório, permitindo verificar seus pontos fracos e fazer com que a Univates repense alguns de seus processos, especialmente no que diz respeito à supervisão do aluno. Conforme indicado por estudantes, empresas e principalmente professores, é necessário rever a forma de acompanhamento dos estagiários. A Univates já faz o que está determinado em lei, que é a supervisão via relatório, mas fica evidente a dificuldade em fazer algum acompanhamento in loco, considerado relevante pelos professores. Dessa forma, sugere-se que a Instituição destine horas aos professores de curso para que esse acompanhamento possa ser realizado de forma efetiva, pois é a supervisão do estágio não obrigatório que dará o caráter pedagógico a essa atividade, permitindo que o aluno reflita sobre a sua escolha profissional. Além disso, a supervisão docente aproxima os professores do mercado de trabalho, possibilitando a constante revisão de currículos e das atividades do curso.

Por fim, cabe destacar que o estudo possibilita verificar que a Univates realiza o seu papel como Instituição de Ensino: oferecer formação de qualidade aos estudantes ao mesmo tempo em que os prepara para o exercício da profissão, por meio da oportunidade de integração dos alunos ao mercado de trabalho. Ao tratar o estágio não obrigatório como uma preparação dos educandos para a profissão, a Univates cria um elo entre a vida estudantil e a vida profissional, contribuindo não somente para a formação e a empregabilidade de seus alunos, mas, também, para sua formação cidadã.

\section{REFERÊNCIAS}

ANDRADE, Arnon de. O estágio supervisionado e a práxis docente. In: __ Site Pessoal. Disponível em: $<$ http://www.educ.ufrn.br/arnon/estagio.pdf $>$. Acesso em: 15 ago. 2012.

BIANCHI, Anna C.; ALVARENGA, Marina; BIANCHI, Roberto. Manual de orientação: estágio supervisionado. São Paulo: Pioneira Thomson Learning, 2001.

BRASIL. Lei $\mathrm{n}^{\circ}$ 6.494, de 7 de dezembro de 1977. Dispõe sobre os estágios de estudantes de estabelecimento de ensino superior e ensino profissionalizante do $2^{\circ}$ Grau e Supletivo e dá outras providências. Disponível em: $<$ http://www.planalto.gov.br/ccivil 03/leis/L6494.htm>. Acesso em: 13 ago. 2012. 
BRASIL. Decreto $n^{\circ}$ 87.497, de 18 agosto de 1982. Regulamenta a Lei $n^{\circ} 6.494$, de 07 de dezembro de 1977, que dispõe sobre o estágio de estudantes de estabelecimentos de ensino superior e de $2^{\circ}$ grau regular e supletivo, nos limites que especifica e dá outras providências. Disponível em: < http://www.planalto.gov.br/ccivil 03/decreto/d87497.htm>. Acesso em: 13 ago. 2012.

BRASIL. Lei no 9.394, de 20 de dezembro de 1996. Estabelece as diretrizes e bases da educação nacional. Disponível em: <http://www.planalto.gov.br/ccivil 03/leis/L9394.htm>. Acesso em: 13 ago. 2012.

BRASIL. Lei $\mathrm{n}^{\mathrm{o}}$ 11.788/2008, de 25 de setembro de 2008. Dispõe sobre o estágio de estudantes; altera a redação do art. 428 da Consolidação das Leis do Trabalho - CLT... Disponível em: < http://www.planalto.gov.br/ccivil_03/_ato2007-2010/2008/lei/111788.htm>. Acesso em: 13 ago. 2012.

LIMA FILHO, Francisco das C. Trabalhador Estagiário. Nova Disciplina. Lei 11.788/08. Portal Jurídico Investidura, Florianópolis/SC, 27 fev. 2009. Disponível em:

$<$ http://www.investidura.com.br/biblioteca-juridica/artigos/direito-trabalho/2818>. Acesso em: 13 ago. 2012.

FREY, Márcia R; FREY, Irineu A. A contribuição do estágio supervisionado na formação do bacharel em Ciências Contábeis. Contabilidade Vista \& Revista, Belo Horizonte, v. 13, n.1, p. 93-104, abr. 2002. Disponível em:

$<$ http://web.face.ufmg.br/face/revista/index.php/contabilidadevistaerevista/article/viewFile/19 $\underline{0 / 184}>$. Acesso em: 16 ago. 2012.

FUJINO, Asa; VASCONSELOS, Michele de O. Estágios: reflexões sobre a ação didáticopedagógica na formação do profissional da informação. Revista CRB-8 Digital. São Paulo, v. 4, n.1, p. 40-58, abr. 2011. Disponível em: $<$ http://revista.crb8.org.br/index.php/crb8digital $>$. Acesso em: 13 ago. 2012.

GIL, Antonio C. Como elaborar projetos de pesquisa. 4a ed. São Paulo: Atlas, 2007.

INSTITUTO EUVALDO LODI. Lei de estágio: tudo o que você precisa saber. Instituto Euvaldo Lodi: Brasília, 2010.

INSTITUTO NACIONAL DE ESTUDOS E PESQUISAS EDUCACIONAIS ANÍSIO TEIXEIRA - INEP. Relatórios Técnicos. Disponível em:

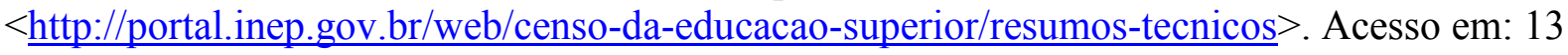
ago. 2012.

MELO, Felipe Luiz Neves Bezerra de. A eficácia da prática do estágio não obrigatório na formação profissional dos estudantes de administração da UFRN: uma análise da aplicação de teorias no mercado de trabalho. 2010. 81 f. Monografia (Graduação) - Curso de Administração, UFRN - Universidade Federal do Rio Grande do Norte. Natal, 2010. 
SCHWARTZ, Maria A. M. Contribuição do estágio supervisionado no desenvolvimento de aptidões e formação de competências. Revista Diálogo Educacional. Curitiba, v. 2, n. 4, p. 105-111, jul./dez. 2001.

SOUZA, Renato B. de. O papel do estágio na formação profisssional do arquivista: a experiência do Curso de Arquivologia da Universidade de Brasília. In: JARDIM, José Maria (Org.). A formação do arquivista no Brasil. Niterói: Editora da Universidade Federal Fluminense, 1999. p. 167-180. Disponível em:

$<$ http://repositorio.bce.unb.br/handle/10482/1446> . Acesso em: 15 ago. 2012.

SOUZA, Vera L. P.; CABRAL, Romilson A.; VIANA, Mari da Penha S. Formação acadêmica: interação e inserção no mercado do trabalho. Disponível em:

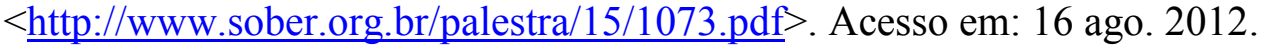

TEIXEIRA, Maurício C.; et al. A percepção dos jovens sobre o estágio e a resistência aos estágios não remunerados. Disponível em:

$<$ www.ibret.org/doc/conferencias/nelma valente.doc $>$. Acesso em: 16 ago. 2012.

TRACZ, Marcelo; DIAS, Anderson N. Estágio supervisionado: um estudo sobre a relação do estágio e o meio produtivo. Disponível em:

$<$ http://www.fag.edu.br/adverbio/artigos/artigo04\%20-\%20adv06.pdf $>$. Acesso em: 16 ago. 2012.

VALVERDE, Franklin Larrubia. O papel pedagógico do estágio na formação do jornalista. 2006. 227 f. Tese (Doutorado) - Departamento de Jornalismo e Editoração/Escola de Comunicações e Artes/USP, São Paulo, 2006. Disponível em:

$<$ http://www.pos.eca.usp.br/sites/default/files/file/bdt/2006/2006-do-valverde franklin.pdf $>$.

Acesso em: 15 ago. 2012.

VASCONCELOS, Michele O. Contribuição dos estágios na formação do profissional da informação: estudo com egressos da Escola de Comunicações e Artes da Universidade de São Paulo (ECA/USP). 2010. 79 f. Monografia (Graduação) - Escola de Comunicações e

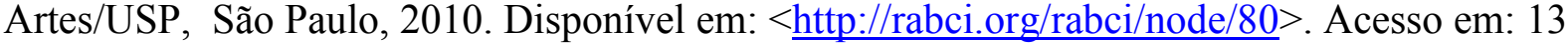
ago. 2012.

WITTMANN, Milton L.; TREVISAN, Marcelo. Estágios extracurriculares: identificação dos resultados na formação de Administradores. Disponível em:

$<$ http://www.angrad.org.br/area_cientifica/artigos/estagios_extracurriculares_identificacao_d os_resultados_na_formacao_de_administradores/709/>. Acesso em: 16 ago. 2012. 